\title{
Microstructures of Poly(1-butadienyloxytrimethylsilane)s Prepared by Aldol Condensation-Type Group Transfer Polymerization
}

\author{
Hiroshi Sumi, Kenji Haraguchi, Yoshihito InaI, Tadamichi HiRabayashi, \\ and Kenji YoKota \\ Department of Materials Science and Engineering, Nagoya Institute of Technology, \\ Gokiso-cho, Showa-ku, Nagoya 466, Japan
}

(Received May 13, 1994)

\begin{abstract}
Three polymers of 1-butadienyloxytrimethylsilane (BdTMS), 3-methyl-1-butadienyloxytrimethylsilane (MeBdTMS), and 3-phenyl-1-butadienyloxytrimethylsilane (PhBdTMS) were prepared by aldol condensation-type group transfer polymerization. Microstructures of these polymers were determined by ${ }^{1} \mathrm{H}$ and ${ }^{13} \mathrm{C}$ NMR. Content of trans-1,4 unit in poly(BdTMS), poly(MeBdTMS), and poly(PhBdTMS) decreased in that order, reflecting $s$-conformation of monomer. The results suggest that this polymerization proceeds via a bicyclic transition state made up of a monomer, propagating chain end, and catalyst. Poly(BdTMS) contained 14\% a 3,4 unit, but poly(MeBdTMS) and poly(PhBdTMS) did not. This suggests that formation of the 3,4 unit depends on the structure of propagating chain end.
\end{abstract}

KEY WORDS Microstructure / Group Transfer Polymerization / Aldol Condensation / 1-Butadienyloxytrimethylsilane / 3-Methyl-1-butadienyloxytrimethylsilane / 3-Phenyl-1-butadienyloxytrimethylsilane / Transition State / Conformation / $\alpha, \beta$-Unsaturated Aldehyde /

In 1986, Webster et al. reported that aldol condensation reactions of silyl vinyl ethers could be applied to a new living polymerization, which is called aldol condensation-type group transfer polymerization (aldol-GTP). ${ }^{1}$ Since aldol-GTP was found to be useful to supply hydrophilic polymer or oligomer with controlled molecular weight and reactive formyl group at its terminal, some investigation has been carried out in the field of synthesis for specially-designed block polymers ${ }^{2}$ and macromonomers. ${ }^{3}$

In order to develop applicable monomers to aldol-GTP, we examined 1-butadienyloxytrimethylsilane (BdTMS) ${ }^{4}$ and its derivatives. ${ }^{5}$ In a series of studies on aldol-GTP of BdTMS, ${ }^{6,7}$ it was revealed that BdTMS could be polymerized with $p$-anisaldehyde as an initiator in the presence of $\mathrm{ZnBr}_{2}$ to give its polymer with a relatively narrow molecular weight distribution $\left(M_{w} / M_{n}=1.3-1.5\right)$. Kinetic investigation of aldol-GTP ${ }^{7,8}$ suggested that the rate determining step is the cationization of the formyl group in the propagating chain end by coordination with $\mathrm{ZnBr}_{2}$. The cationic site is subject to nucleophilic addition of the monomer. Furthermore, it was found that selective aldol-GTP for $E$-isomers took place. ${ }^{5}$

In this paper, microstructures of polymers prepared by aldol-GTP of BdTMS and its derivatives are investigated in details. On the basis of a comparison of their microstructures, the most reasonable mechanism for aldol-GTP of BdTMS is discussed.

\section{EXPERIMENTAL}

\section{Materials}

1-Butadienyloxytrimethylsilane (BdTMS), 3-methyl-1-butadienyloxytrimethylsilane 
Microstructures of Polymers Prepared by Aldol-GTP

Table I. Aldol-GTP of BdTMS, MeBdTMS and PhBdTMS with $p$-anisaldehyde and $\mathrm{ZnBr}_{2}$ in toluene

\begin{tabular}{|c|c|c|c|c|c|c|c|c|}
\hline \multirow{2}{*}{ Monomer } & {$[\mathrm{M}]_{0}^{\mathrm{a}}$} & {$[\mathrm{I}]_{0}^{\mathrm{a}} \times 10^{2}$} & {$[\mathrm{C}]_{0}^{\mathrm{a}} \times 10^{2}$} & Temp & Time & Yield & \multirow{2}{*}{$M_{n}^{\mathrm{b}} \times 10^{-3}$} & \multirow{2}{*}{$\frac{M_{\mathrm{w}}^{\mathrm{b}}}{M_{n}}$} \\
\hline & & $\mathrm{moll}^{-1}$ & & ${ }^{\circ} \mathrm{C}$ & $\mathrm{h}$ & $\%$ & & \\
\hline BdTMS & 1.04 & 0.3 & $1.0^{\mathrm{c}}$ & -78 & 96 & 72 & 42.3 & 1.30 \\
\hline MeBdTMS & 1.48 & 1.5 & $1.7^{\mathrm{c}}$ & 0 & 3 & 81 & 10.0 & 1.25 \\
\hline PhBdTMS & 1.05 & 1.0 & $3.0^{\mathrm{d}}$ & 0 & 1 & 50 & 10.0 & 1.20 \\
\hline
\end{tabular}

a Monomer; I, p-anisaldehyde; $\mathrm{C}, \mathrm{ZnBr}_{2}$.

b Determined by GPC, calibrated with standard polystyrene samples.

c $\mathrm{ZnBr}_{2}$ was used as $1.4 \mathrm{moll}^{-1}$ solution in diethyl ether.

d Solid $\mathrm{ZnBr}_{2}$ was used.

(MeBdTMS), and 3-phenyl-1-butadienyloxytrimethylsilane (PhBdTMS) were prepared according to procedures described previously. ${ }^{5}$ Their polymers were prepared by aldol-GTP which were carried out by the use of $p$-anisaldehyde and $\mathrm{ZnBr}_{2}$ as an initiator and catalyst, respectively. ${ }^{5,7,8}$ The polymerization conditions and results are summarized in Table I.

\section{Measurements}

${ }^{1} \mathrm{H}$ and ${ }^{13} \mathrm{C}$ NMR spectra were recorded with a Varian XL-200 spectrometer at room temperature. Sample concentration in deuterochloroform wạ $5-10 \mathrm{wt} \%$ for ${ }^{1} \mathrm{H}$ NMR measurement and $10-30 \mathrm{wt} \%$ for ${ }^{13} \mathrm{C}$ NMR measurement. Chloroform for ${ }^{1} \mathrm{H}$ and $\mathrm{CDCl}_{3}$ for ${ }^{13} \mathrm{C}$ were used as internal standards.

\section{RESULTS}

Microstructure of Poly(BdTMS) Prepared by Aldol-GTP

${ }^{1} \mathrm{H}$ NMR spectrum of poly(BdTMS) prepared by aldol-GTP is shown in Figure 1a with assignments of signals. The repeating units in the poly(BdTMS) consisted of 1,4 and 3,4 structures. In the resonance region of olefinic protons, signals at 6.1 and $4.7 \mathrm{ppm}$ were assigned to the 3,4 structure and signal at $5.5 \mathrm{ppm}$ to the 1,4 structure. These assignments were supported by comparing with the assignments of poly(1-ethoxybutadiene) prepared by cationic polymerization. ${ }^{9}$ The assignments of the signals due to 3,4 structure were confirmed by triethylamine-catalyzed methanolysis $^{10}$ of poly(BdTMS). When poly(BdTMS) was treated with methanol and triethylamine, the trimethylsilyl enolate moiety in the 3,4 unit rapidly underwent methanolysis as shown in Scheme 1. However, the methanolysis of the trimethylsilyl ether moiety in the 1,4 unit was very slow.

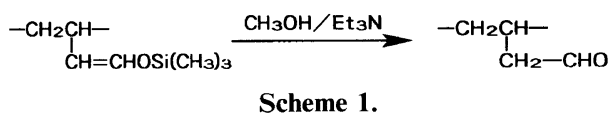

In the ${ }^{1} \mathrm{H}$ NMR spectrum of the polymer after methanolysis, the signals at 6.1, 4.7, and $0.2 \mathrm{ppm}\left(\mathrm{b}^{\prime}, \mathrm{c}^{\prime}\right.$, and $\left.\mathrm{a}^{\prime}\right)$ in Figure 1a disappeared and a signal due to formyl protons appearing at $9.7 \mathrm{ppm}$. In the IR spectrum of the polymer, an absorption due to $\mathrm{C}=\mathrm{C}\left(1660 \mathrm{~cm}^{-1}\right)$ in 3,4 unit disappeared and a new absorption due to formyl $\mathrm{C}=\mathrm{O}\left(1720 \mathrm{~cm}^{-1}\right)$ appeared. Consequently, the 3,4 unit as well as 1,4 unit existed in the poly(BdTMS). In Figure 1a, no signals due to vinyl group in 1,2 unit were observed. The absence of the 1,2 unit was also confirmed by hydrogenation of poly(BdTMS). If there should be a 1,2 unit in the resulting polymer, any vinyl group would be converted to an ethyl group by hydrogenation with Wilkinson's catalyst. ${ }^{11}$ However, no signals due to the ethyl group derived from vinyl side chain in 1,2 unit were observed in the ${ }^{13} \mathrm{C}$ NMR spectrum of 


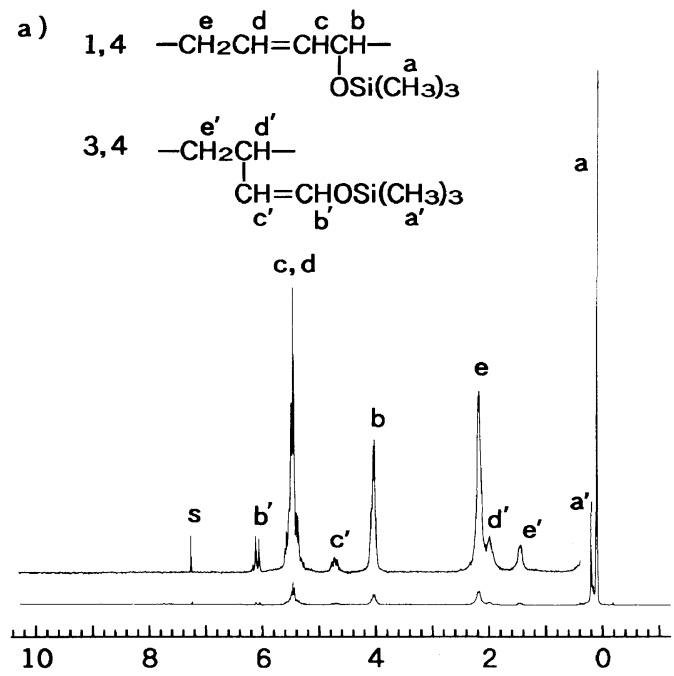

b)
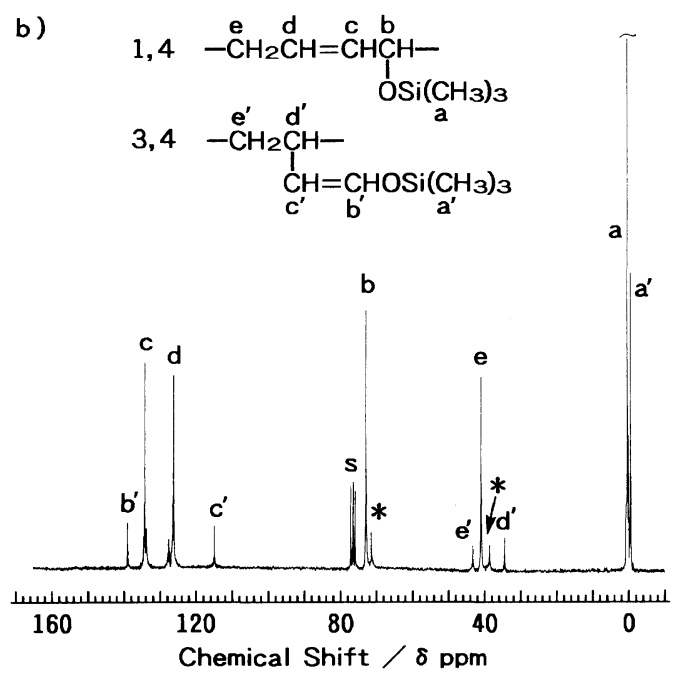

Figure 1. (a) ${ }^{1} \mathrm{H}$ NMR and (b) ${ }^{13} \mathrm{C}$ NMR spectra of poly(BdTMS) in $\mathrm{CDCl}_{3}$ : s, solvent; *, see the text.

hydrogenated poly(BdTMS). To produce the 1,2 unit by aldol-GTP, BdTMS has to behave as a vinyl substituted vinyloxytrimethylsilane. It has been found that the polymerizability of vinyloxytrimethylsilane was lower than that of BdTMS by aldol group transfer copolymerization of BdTMS and vinyloxytrimethylsilane. ${ }^{12}$ Therefore, it can be assumed that the 1,2addition of BdTMS hardly occurs.

On the basis of the intensities of olefinic ${ }^{1} \mathrm{H}$
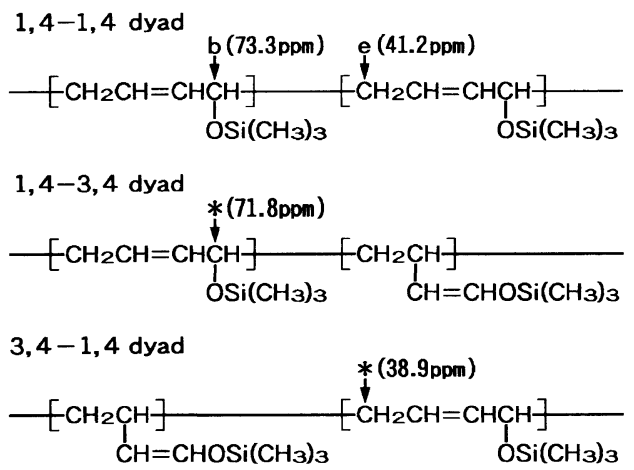

Scheme 2.

NMR signals in 1,4 and 3,4 units, poly(BdTMS) consists of about $86 \% \quad 1,4$ and $14 \%$ 3,4 units.

The ${ }^{13} \mathrm{C}$ NMR spectrum of the poly(BdTMS) is shown in Figure 1b with assignments of signals. The assignments were made by reference to assignments of polybutadienes $^{13}$ and on the basis of the DEPT spectrum of the poly(BdTMS). The main signals of $\mathrm{a}-\mathrm{e}$ and $\mathrm{a}^{\prime}-\mathrm{e}^{\prime}$ were assigned to 1,4 and 3,4 units, respectively. Two signals at 38.9 and $71.8 \mathrm{ppm}$ (marked by $*$ in Figure $1 \mathrm{~b}$ ) were assigned to the methylene and methine carbons in the 1,4 unit adjacent to 3,4 unit, respectively, as shown in Scheme 2. The assignments of the two signals can be explained by dyad distribution of 1,4 and 3,4 units. 3,4 Unit content was $14 \%$ by ${ }^{1} \mathrm{H}$ NMR. When the distribution of 3,4 units in the poly(BdTMS) obeys Bernoullian statistics, dyad proportions of 1,4 and 3,4 units are $P_{11}=0.74, P_{12}=P_{21}=$ 0.12 , and $P_{22}=0.02$, where the subscripts 1 and 2 express 1,4 and 3,4 units, respectively. Signal intensity ratios were $5.8\left(=I_{73.3} / I_{71.8}\right)$ for siloxymethine carbons (b and $*$ in Figure 1b) and $6.2 \quad\left(=I_{41.2} / I_{38.9}\right)$ for methylene carbons (e and $*$ in Figure $1 b$ ). These values are in agreement with 6.1 calculated by $P_{11} / P_{12}$ or $P_{11} / P_{21}$.

The IR spectrum of poly(BdTMS) showed absorption at $960 \mathrm{~cm}^{-1}$ characteristic of trans $-1,4$ unit but no absorption at $720 \mathrm{~cm}^{-1}$ 
characteristic of cis-1,4 unit. ${ }^{13} \mathrm{C}$ NMR spectrum of poly(BdTMS) showed no signals due to geometric differences, particularly methylene carbon signal. Therefore, the geometry of 1,4 unit in the poly(BdTMS) is all trans.

\section{Microstructure of Poly(MeBdTMS) Prepared} by Aldol-GTP

${ }^{1} \mathrm{H}$ NMR spectrum of poly(MeBdTMS) prepared by aldol-GTP is shown in Figure 2a with assignments of signals. The signals due to only 1,4 structure were observed in the ${ }^{1} \mathrm{H}$ NMR spectrum. Small signals at 3.77 and 6.8-7.2 ppm were assigned to $\mathrm{CH}_{3} \mathrm{O}$ - and $-\mathrm{C}_{6} \underline{\mathrm{H}}_{4}-$ of initiator ( $p$-anisaldehyde) residue.
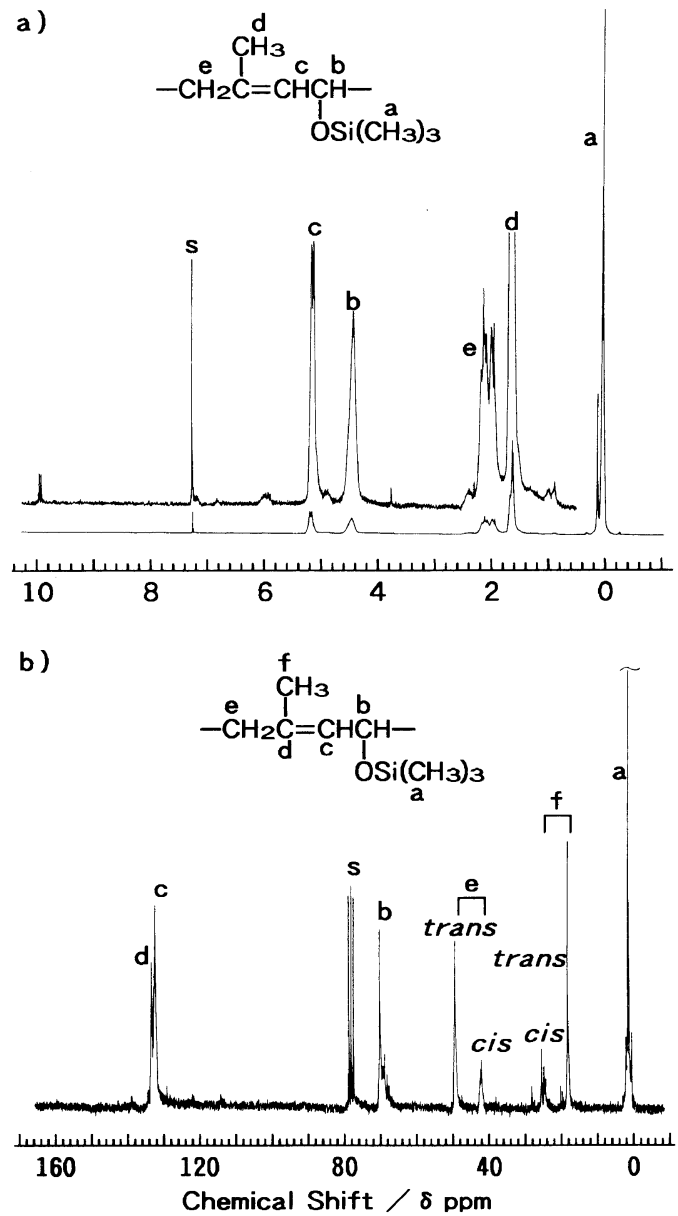

Figure 2. (a) ${ }^{1} \mathrm{H}$ NMR and (b) ${ }^{13} \mathrm{C}$ NMR spectra of poly(MeBdTMS) in $\mathrm{CDCl}_{3}$ : s, solvent.
Other small signals at $2.4,4.9,5.9$, and $9.95 \mathrm{ppm}$ were assigned to the protons in the propagating chain end: $-\mathrm{C} \underline{\mathrm{HOSi}}\left(\mathrm{CH}_{3}\right)_{3}-\mathrm{CH}_{2}-$ $\mathrm{C}\left(\mathrm{CH}_{3}\right)=\mathrm{C} \underline{\mathrm{H}}-\mathrm{C} \underline{\mathrm{HO}}$. On the basis of their intensities, the initiator residue and the propagating chain end were in the ratio $1: 1$. This correspondence suggests that one molecule of initiator yields one polymer always having an $\alpha, \beta$-unsaturated aldehyde moiety at its propagating end.

${ }^{13} \mathrm{C}$ NMR spectrum of the poly(MeBdTMS) is shown in Figure $2 b$ with assignments of signals. The assignments was made by reference to the assignments of polyisoprenes ${ }^{13}$ and on the basis of the DEPT spectrum of the poly(MeBdTMS). The chemical shifts of the methyl and methylene carbons in the poly(MeBdTMS) are lower field than those of the corresponding carbons in the polyisoprene owing to electron-withdrawing character of the trimethylsiloxy group. Both the methyl and methylene carbons in the poly(MeBdTMS) gave two signals due to $c i s-1,4$ and trans $-1,4$ structures. The assignments were based on the following facts. The chemical shift difference of $6.9 \mathrm{ppm}$ between two methyl carbon signals of the poly(MeBdTMS) is close to the difference of $7.5 \mathrm{ppm}$ between methyl carbon signal of trans-1,4-polyisoprene and that of cis-1,4polyisoprene. Similarly the chemical shift difference of $7.3 \mathrm{ppm}$ between two methylene carbon signals of the poly(MeBdTMS) is close to the difference of $7.4 \mathrm{ppm}$ between methylene carbon signal of trans-1,4-polyisoprene and that of cis-1,4-polyisoprene. Calculation of ${ }^{13} \mathrm{C}$ chemical shifts of poly(MeBdTMS) was based on the contribution of the trimethylsiloxy group to the ${ }^{13} \mathrm{C}$ chemical shifts. ${ }^{13} \mathrm{C}$ chemical shift differences between polybutadiene and poly(BdTMS) provide a global contribution of the trimethylsiloxy group to the ${ }^{13} \mathrm{C}$ chemical shifts. ${ }^{13} \mathrm{C}$ chemical shift differences between the corresponding carbons of trans-1,4-polybutadiene and 1,4 unit of poly(BdTMS) were calculated and are presented in the footnote of Table II. Table II 
Table II. ${ }^{13} \mathrm{C}$ chemical shifts of poly(MeBdTMS) and poly(PhBdTMS)

\begin{tabular}{|c|c|c|c|c|c|c|}
\hline & & & \multicolumn{4}{|c|}{${ }^{13} \mathrm{C}$ chemical shifts/ppm } \\
\hline & & & $\mathrm{C}_{\mathrm{b}}$ & $\mathrm{C}_{\mathrm{c}}$ & $\mathrm{C}_{\mathrm{d}}$ & $\mathrm{C}_{\mathrm{e}}$ \\
\hline \multirow[t]{4}{*}{ Poly(MeBdTMS) } & trans & (obsd) & 69.5 & 131.9 & 132.9 & 48.7 \\
\hline & & $(\text { calcd })^{\mathbf{a}}$ & 67.9 & 129.8 & 132.2 & 48.7 \\
\hline & cis & (obsd) & 68.7 & 131.9 & 132.9 & 41.5 \\
\hline & & $(\text { calcd })^{\mathrm{a}}$ & 67.8 & 130.5 & 132.5 & 41.2 \\
\hline \multirow[t]{4}{*}{ Poly(PhBdTMS) } & trans & (obsd) & 68.5 & 136.0 & 142.0 & 48.5 \\
\hline & & $(\text { calcd })^{a}$ & 68.7 & 138.7 & 136.8 & 48.4 \\
\hline & cis & (obsd) & 68.5 & 136.0 & 142.0 & 39.0 \\
\hline & & $(\text { calcd })^{\mathbf{a}}$ & 68.7 & 138.7 & 136.8 & 38.6 \\
\hline
\end{tabular}

${ }^{\text {a }}$ Contribution of the trimethylsiloxy group to ${ }^{13} \mathrm{C}$ chemical shifts of diene polymer estimated from trans-1,4-polybutadiene and poly(BdTMS).

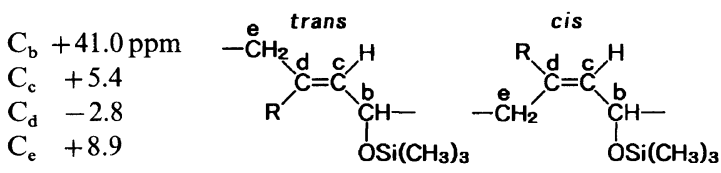

lists ${ }^{13} \mathrm{C}$ chemical shifts observed for poly(MeBdTMS) and calculated by application of the contribution of the trimethylsiloxy group to polyisoprene. The calculated chemical shifts were in agreement with the observed ones.

The poly(MeBdTMS) consists of about $69 \%$ trans $-1,4$ and $31 \%$ cis-1,4 units on the basis of the intensities of the two methyl and methylene carbon signals.

\section{Microstructure of Poly(PhBdTMS) Prepared by Aldol-GTP}

The ${ }^{1} \mathrm{H}$ NMR spectrum of poly(PhBdTMS) prepared by aldol-GTP is shown in Figure 3a with assignments of signals. The signals were broad because the main chain can take various conformations and slow segment movement owing to bulky phenyl and trimethylsiloxy substituents. Main signals could be assigned to only the 1,4 structure. Sharp small signals are due to unchanged $Z$-PhBdTMS monomer which did not undergo the aldol-GTP. ${ }^{5}$

The ${ }^{13} \mathrm{C}$ NMR spectrum of the poly(PhBdTMS) is shown in Figure $3 \mathrm{~b}$ with assignments of signals. The assignments were made by reference to the assignments of poly(2-phenylbutadiene) ${ }^{14}$ and on the basis of the DEPT spectrum of the poly(PhBdTMS). The methylene carbon in the poly(PhBdTMS) gave two signals due to cis-1,4 and trans-1,4 structures. The signal at $38-40 \mathrm{ppm}$ was assigned to the methylene carbon in cis-1,4 unit, and the other signal at $47-50 \mathrm{ppm}$ was assigned to the methylene carbon in trans1,4 unit, on the basis of the methylene carbon chemical shifts of the cis-1,4 and trans-1,4poly(2-phenylbutadiene)s (29.7 and $39.5 \mathrm{ppm}$, respectively). Table II lists ${ }^{13} \mathrm{C}$ chemical shifts observed for poly(PhBdTMS) and calculated by application of the contribution of the trimethylsiloxy group to poly(2-phenylbutadiene). Both chemical shifts agreed well, except for the olefinic carbons.

The poly(PhBdTMS) consists of about $17 \%$ trans $-1,4$ and $83 \%$ cis- 1,4 units on the basis of the intensities of the two methylene carbon signals.

\section{DISCUSSION}

\section{Determination of 1,4 Unit Geometry}

The microstructure contents of poly- 
a )
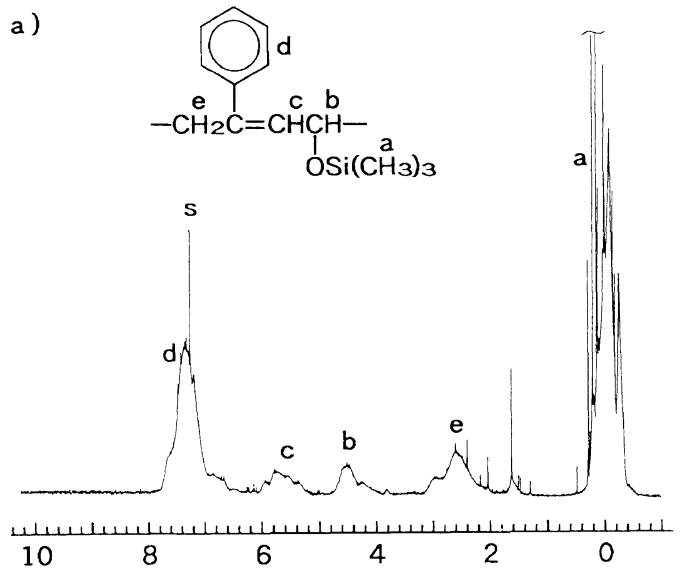

b)
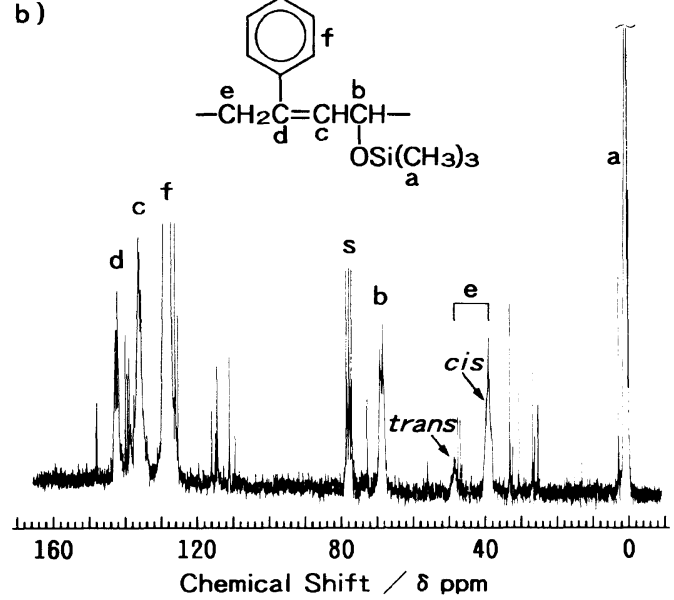

Figure 3. (a) ${ }^{1} \mathrm{H}$ NMR and (b) ${ }^{13} \mathrm{C}$ NMR spectra of poly(PhBdTMS) in $\mathrm{CDCl}_{3}$ : s, solvent.

(BdTMS), poly(MeBdTMS), and poly(PhBdTMS) are summarized in Table III. The content of trans-1,4 unit decreased in the order of $\mathrm{H}-, \mathrm{CH}_{3}-$, and $\mathrm{C}_{6} \mathrm{H}_{5}-$ substituents of monomers. The results suggest that an olefinic geometry of 1,4 unit reflects a $s$-conformation of butadiene moiety of monomers. It was pointed out that a conformation of the conjugated diene skeleton of incoming monomer must remain unchanged at a transition state of propagation on aldol-GTP. The olefinic geometry of the new propagating end reflects the conformation of an incoming monomer, as shown in Scheme 3. Therefore, the olefinic
Table III. Microstructures of poly(BdTMS)s prepared by aldol-GTP

\begin{tabular}{|c|c|c|c|c|}
\hline \multirow{2}{*}{ Polymer } & \multirow{2}{*}{$\mathrm{R}$} & \multicolumn{3}{|c|}{$\begin{array}{c}\text { Content of } \\
\text { microstructure } / \%\end{array}$} \\
\hline & & trans- 1,4 & $c i s-1,4$ & 3,4 \\
\hline Poly(BdTMS) & $\mathrm{H}$ & 86 & 0 & 14 \\
\hline Poly(MeBdTMS) & $\mathrm{CH}_{3}$ & 69 & 31 & 0 \\
\hline Poly(PhBdTMS) & $\mathrm{C}_{6} \mathrm{H}_{5}$ & 17 & 83 & 0 \\
\hline $\begin{array}{l}\mathrm{CH}- \\
\mathrm{OSi}\left(\mathrm{CH}_{3}\right)_{3}\end{array}$ & & $\mathrm{Si}\left(\mathrm{CH}_{3}\right)_{3}$ & $\mathrm{H}_{2}-\underset{\mathrm{I}}{\mathrm{I}}-\underset{\mathrm{I}}{\mathrm{C} H}=$ & $\left(\mathrm{CH}_{3}\right)_{3}$ \\
\hline trans $-1,4$ & cis-1, & & 3,4 & \\
\hline
\end{tabular}

geometry of 1,4 unit depends on whether the incoming monomer takes s-cis or s-trans conformation. With increasing bulkiness of the 3-position substituent, the 1,3-disubstituted monomer prefers $s$-cis conformation to s-trans conformation so as to keep the coplanarity.

UV spectroscopy provides information regarding the $s$-conformation of conjugated diene compounds. Molar absorptivities, $\varepsilon_{\max }$, of BdTMS, MeBdTMS, and PhBdTMS were $24400\left(\lambda_{\max }=233 \mathrm{~nm}\right), 21100\left(\lambda_{\max }=237 \mathrm{~nm}\right)$, and $11100\left(\lambda_{\max }=247 \mathrm{~nm}\right)$, respectively. Large $\varepsilon_{\max }$ of BdTMS indicates that s-trans conformation is predominant, while small $\varepsilon_{\max }$ of $\mathrm{PhBdTMS}$ indicates that $s$-cis conformation is predominant. ${ }^{15}$ The 1,4 unit geometry in poly(BdTMS) was all trans because the s-trans conformation is favorable to BdTMS. Content of cis-1,4 unit in poly(PhBdTMS) was higher than that of trans-1,4 unit because the s-cis conformation is favorable to PhBdTMS in order to avoid steric crowding between phenyl and trimethylsiloxy group. The methyl substituent of MeBdTMS is not as bulky as phenyl substituent, and thus the cis/trans ratio of 1,4 unit geometry in poly(MeBdTMS) is intermediate between that in poly(BdTMS) and that in poly(PhBdTMS). 

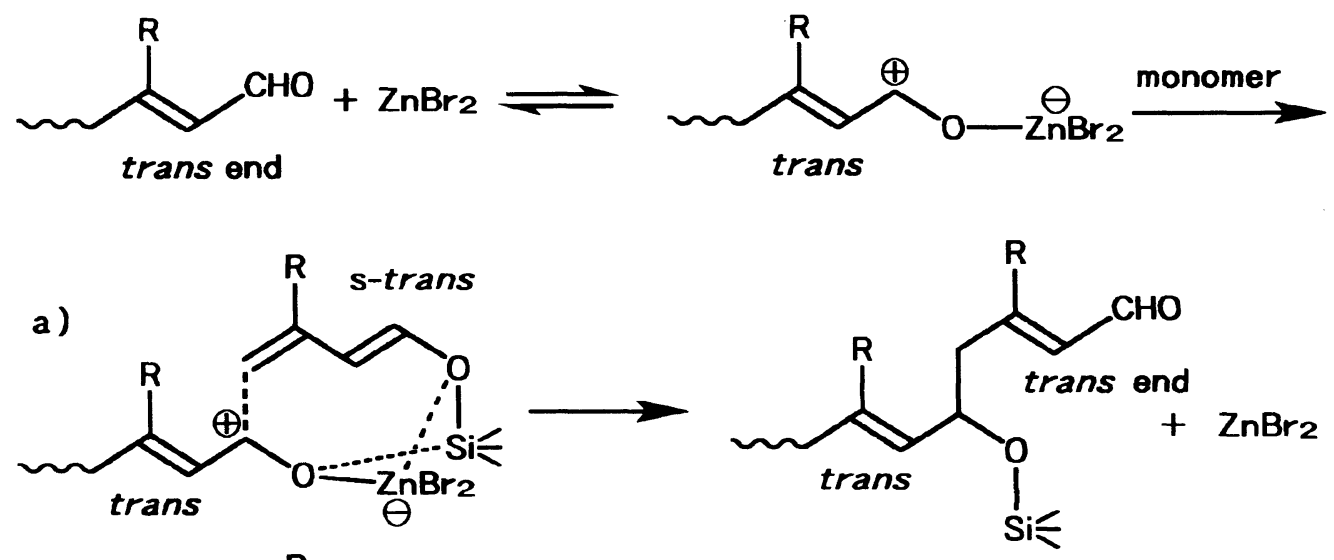

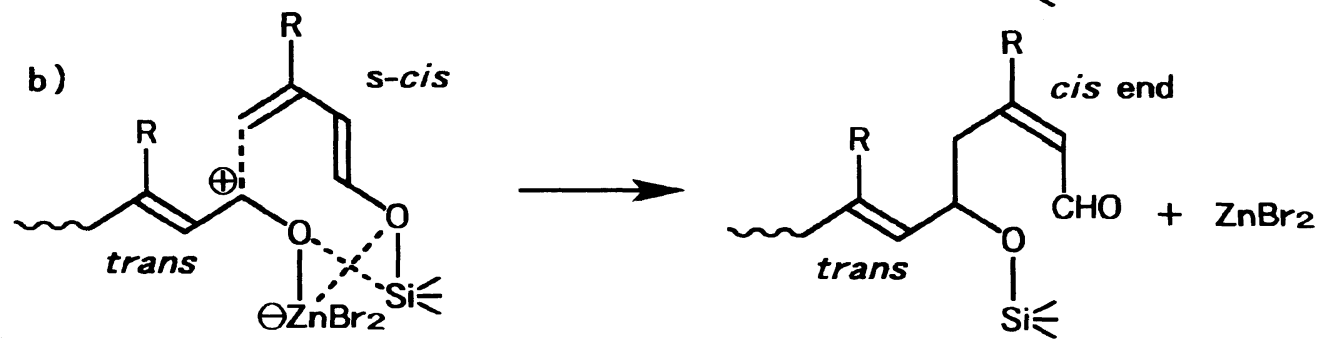

Scheme 3.
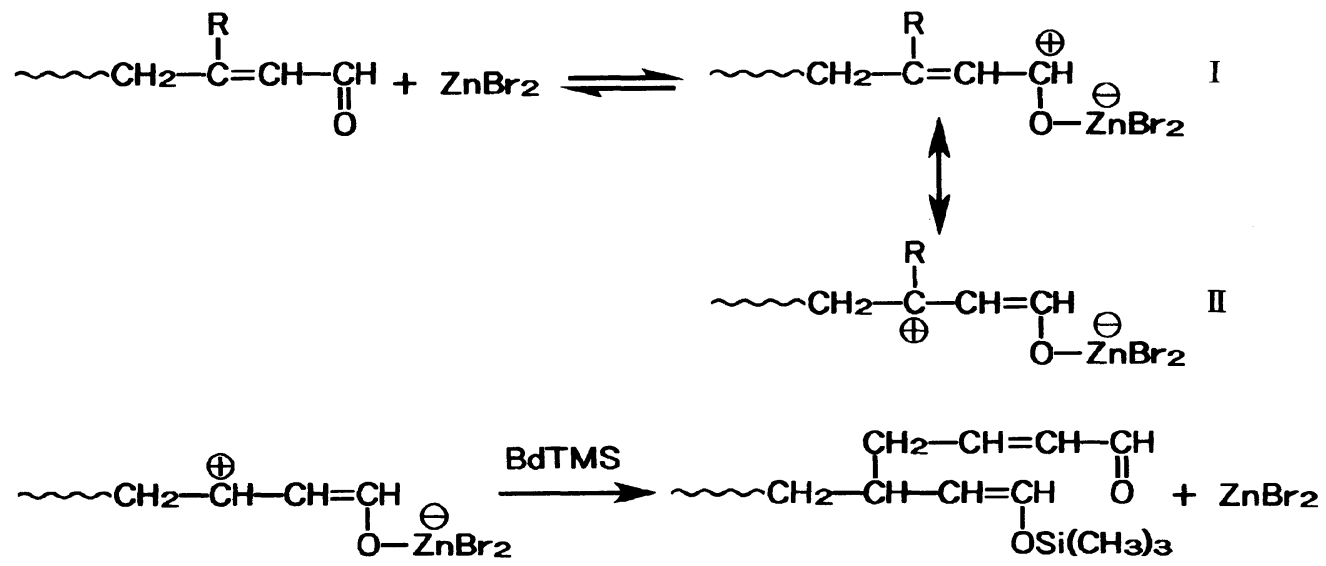

Scheme 4.

\section{Formation of the 3,4 Unit}

The 3,4 unit existed only in poly(BdTMS). The structure of propagating chain end of three polymers prepared by aldol-GTP is $\alpha, \beta$ unsaturated aldehyde. Carbocation generated by coordination of the end formyl group with $\mathrm{ZnBr}_{2}$ is in a resonance hybrid of I and II in Scheme 4. Carbocations II as well as I can undergo nucleophilic addition of monomer. However, carbocation II of the poly(MeBdTMS) end or poly(PhBdTMS) end is presumably less reactive than that of poly(BdTMS) end owing to stabilization by a methyl or phenyl substituent, and furthermore is difficult to undergo nucleophilic monomer addition owing to steric hindrance of the substituent. On 
aldol-GTP of BdTMS, monomer reacts with not only carbocation I but also II to yield the 3,4 unit, as shown in Scheme 4. The reaction proceeds perhaps via the mechanism shown in Scheme 3, though the coplanarity of conjugated system is distorted slightly. Extension of the conjugated system by phenyl or methyl substituent may prevent such distortion.

\section{REFERENCES}

1. D. Y. Sogah and O. W. Webster, Macromolecules, 19, 1775 (1986); F. P. Boettcher, Makromol. Chem., Makromol. Symp., 13/14, 193 (1988).

2. W. Risse and R. H. Grubbs, Macromolecules, 22, 1558 (1989).

3. B. Charleux and C. Pichot, Polymer, 34, 195 (1993).

4. T. Hirabayashi, T. Ito, and K. Yokota, Polym. J., 20, 1041 (1988).

5. H. Sumi, K. Haraguchi, Y. Inai, T. Hirabayashi, and
K. Yokota, Polym. J., in press.

6. T. Hirabayashi, T. Kawasaki, and K. Yokota, Polym. J., 22, 287 (1990).

7. H. Sumi, T. Hirabayashi, Y. Inai, and K. Yokota, Polym. J., 24, 669 (1992).

8. H. Sumi, A. Suzuki, T. Hirabayashi, Y. Inai, and K. Yokota, Polym. J., 26, 705 (1994).

9. M. Otsuki, T. Masuda, and T. Higashimura, $J$. Polym. Sci., Polym. Chem. Ed., 14, 1157 (1976).

10. X. Creary and A. J. Rollin, J. Org. Chem., 44, 1017 (1979).

11. Y. Mori, H. Sumi, T. Hirabayashi, Y. Inai, and K. Yokota, Macromolecules, 27, 1051 (1994).

12. H. Sumi, K. Ishikawa, Y. Inai, T. Hirabayashi, K. Yokota, Polym. J., submitted.

13. M. W. Duch and D. M. Grant, Macromolecules, 3, 165 (1970).

14. T. Suzuki, Y. Tsuji, Y. Takegami, and H. J. Harwood, Macromolecules, 12, 234 (1979).

15. E. L. Eliel, "Stereochemistry of Carbon Compounds," McGraw-Hill Book Company, Inc., New York, N.Y., 1962, Chapter 12. 